\title{
ESCOLA DE MÚSICA DO ESTADO DO MARANHÃO - EMEM: UM ESTUDO DE CASO HISTÓRICO-ORGANIZACIONAL PARA PROPOSIÇÃO DE ACÕ̃ES ADMINISTRATIVAS
}

\author{
http://dx.doi.org/10.5902/2318133825295
}

\author{
Ricieri Carlini Zorzal \\ Universidade Federal do Maranhão, Brasil. \\ Ana Neuza Araújo Ferreira \\ Escola de Música do Estado do Maranhão, Brasil.
}

\begin{abstract}
Resumo
O presente trabalho tem por objetivo propor ações, no âmbito da gestão escolar em uma instituição pública de ensino de música em nível fundamental e médio, que possam incidir sobre o índice de evasão identificado nessa instituição. Para tanto, elegeu-se a Escola de Música do Estado do Maranhão - Emem - como objeto de estudo e adotou-se o estudo de caso históricoorganizacional com viés quali-quantitativo como abordagem metodológica. Dessa forma, procedeu-se a uma pesquisa documental, a gravação em áudio de entrevistas conduzidas junto ao corpo docente e ao corpo técnico-administrativo, bem como a aplicação de um questionário junto ao corpo discente da instituição. Por fim, elencam-se sugestões de ações no âmbito da gestão escolar em três dimensões: a relação administrativa com as instâncias superiores, decisões no âmbito do colegiado acadêmico e ações no campo pedagógico.

Palavras-chave: Escola de Música do Estado do Maranhão, estudo de caso históricoorganizacional, gestão escolar.
\end{abstract}

\section{MUSIC SCHOOL OF MARANHÃO - EMEM: A HISTORICAL-ORGANIZATIONAL CASE STUDY IN ORDER TO PROPOSE CURRENT ADMINISTRATIVE ACTIONS}

\begin{abstract}
This work aspires to propose administrative actions within a public music school called Escola de Música do Estado do Maranhão - Emem. Methodologically, it was conducted a historicalorganizational case study with quali-quantitatives procedures such as documentary research, audio recorded interviews and questionnaire. Lastly, this work points up administrative actions to support the Emem's development in three different fronts: its administrative relationship with the Maranhão's public educational department; collegiate decisions; and pedagogical actions.

Key-words: Music School of Maranhão, historical-organizational case study, school management.
\end{abstract}




\section{Introdução}

criação de escolas e conservatórios de música públicos no Nordeste Brasileiro levou cem anos para acontecer em todos os Estados da região. Nesse ínterim, iniciado no final do século 19 com o Conservatório de Música da Bahia, foi criada, por meio da lei estadual n. 5.267/1974, a Escola de Música do Estado do Maranhão - Emem.

Atualmente a Emem é a única instituição pública de ensino musical a atender a população maranhense dos anos iniciais da formação musical ao ensino técnico ${ }^{1}$. Além disso, a instituição cumpre um papel de pré-formação para aqueles que desejam seguir seus estudos nos cursos superiores de Música (Subtil, 2011). No Estado do Maranhão esses cursos são oferecidos pela Universidade Federal do Maranhão e pela Universidade Estadual do Maranhão. Por sua importância no contexto da educação musical do Estado a Emem tem sido objeto de pesquisa de diversos trabalhos (Costa, 1995; Rodrigues, 2011; Ferreira, 2014; Silva, 2015).

Não obstante o importante papel formativo que tem cumprido ao longo desses anos, a história da Emem encontra similaridades entre seus congêneres na região nordestina. Questões das mais diversas origens têm transformado a sobrevivência dessas instituições em um exercício de resistência daqueles que lutam por sua manutenção. Em outras palavras, instabilidade de recursos orçamentários, problemas de estrutura física, e sensibilidade às gestões políticas são, por exemplo, alguns dos insistentes aspectos da história administrativa dessas instituições (Zorzal; Ferreira, 2016).

Interessados no comportamento da Emem dentro desse panorama regional observase que a longa existência da instituição foi traduzida por um número de apenas 119 formados até o ano de 2014 (Ferreira, 2014). Esse dado sugere alguma heterotecnia no trabalho desempenhado pela Emem, que chegou a matricular mais de 2300 alunos em um único ano.

Por sua singularidade e pela possibilidade de generalização dos resultados aos outros conservatórios da região nordestina, a Emem desenha-se como um estudo de caso digno de atenção. Assim, motivados pelos números apresentados no parágrafo anterior, questão que mobilizou este trabalho é a seguinte: Como as ações administrativas da Emem podem contribuir para uma melhoria do índice de evasão?

É mister notar que esta questão delimita o objeto de estudo às ações que estão no campo de ação direta da administração da escola. Dessa forma, variáveis externas que indubitavelmente são correlacionadas ao índice de evasão, tais como as variáveis antecedentes dos alunos (D'abreu; Marturano, 2010) ou questões relativas à inserção profissional dos egressos no meio musical (Pimentel, 2015), serão abordadas secundariamente no escopo deste trabalho. Nesse sentido, pondera Alves-Mazzotti (2006) que "uma escola, como caso, deve ser estudada como um sistema delimitado, embora a influência de diferentes aspectos que se ligam a esse sistema, como o contexto físico, sociocultural, histórico e econômico em que está inserida a escola, as normas da Secretaria de Educação etc., não deva ser ignorada" (p. 641).

1 Oficialmente, a Emem é uma escola de nível médio. O curso Fundamental foi recentemente estruturado e, até o momento, não há emissão de certificado ou diploma para o mesmo. 


\section{Metodologia}

A questão exposta acima e diversas referências na área de metodologia científica ratificam o estudo de caso como proposta metodológica para a presente pesquisa:

Em geral, os estudos de caso representam a estratégia preferida quando se colocam questões do tipo "como" e "por que", quando o pesquisador tem pouco controle sobre os eventos e quando o foco se encontra em fenômenos contemporâneos inseridos em algum contexto da vida real. (Yin, 2005, p. 19)

Contudo, há certo acordo na literatura que o estudo de caso não determina estratégias e técnicas a serem adotadas. Entende Triviños que estudo de caso é "uma categoria de pesquisa cujo objeto é uma unidade que se analisa aprofundadamente" (2012, p. 133). Nesse mesmo sentido Goldenberg (2004) afirma que

o estudo de caso não é uma técnica específica, mas uma análise holística, a mais completa possível, que considera a unidade social como um todo, seja um indivíduo, uma família, uma instituição ou uma comunidade, com o objetivo de compreendê-los em seus próprios termos. (p. 33)

Portanto, a opção pelo estudo de caso demanda escolhas metodológicas posteriores para a determinação de como os dados serão recolhidos e tratados. Inicialmente, os pesquisadores demonstraram interesse pela vida da instituição. Essa escolha é definida por Triviños (2012) como estudo de caso histórico-organizacional. Como consequência dessa escolha realizou-se uma pesquisa documental com a análise dos seguintes documentos: livro de registros dos alunos formados pela instituição; dados dos percentuais de matriculados nos últimos 10 anos; últimos editais para o processo seletivo de entrada de novos alunos; dossiê do corpo docente; relatórios semestrais e anuais de atividades desenvolvidas e diários oficiais dos concursos públicos realizados para professor da instituição.

Além disso, para uma maior imersão na questão proposta, os pesquisadores estabeleceram três unidades de análise para ajudar na compreensão do caso. Dessa forma foram investigadas as percepções do corpo docente, do corpo técnicoadministrativo e do corpo discente da instituição. Assim, foram elaboradas entrevistas semiestruturadas para o corpo docente e o corpo técnico-administrativo e um questionário misto para o corpo discente.

Pelo exposto, a construção da proposta metodológica fez emergir um desenho qualiquantitativo para o estudo de caso histórico-organizacional. Nesse sentido, "o estudo de caso como estratégia de pesquisa caracteriza-se justamente por esse interesse em casos individuais e não pelos métodos de investigação, os quais podem ser os mais variados, tanto qualitativos como quantitativos" (Alves-Mazzotti, 2006, p. 641).

Uma descrição mais detalhada da abordagem metodológica para cada uma das três unidades de análise estabelecidas é dada a seguir.

\section{Corpo docente}

O corpo docente da Emem foi dividido em três grupos amostrais. O primeiro grupo amostral foi compreendido pelos professores que trabalharam na escola no período entre a criação da Emem e o ano de 1991. O segundo grupo amostral foi constituído pelos 
professores aprovados no concurso público realizado em 1992. O terceiro grupo amostral foi constituído pelos professores aprovados no concurso público realizado em 2002. Dessa forma, cinco professores aceitaram participar da pesquisa, sendo dois professores do primeiro grupo, um do segundo grupo e dois do terceiro grupo.

Os cinco professores participantes da pesquisa foram individualmente submetidos a uma entrevista semiestruturada composta por quatro questões: como você avalia o atual perfil da Emem e sua relação com o mercado de trabalho para os técnicos em Música no Maranhão? Como você avalia o corpo docente que a Emem possui hoje? Em sua opinião, quais fatores afetam o desenvolvimento da atividade pedagógica da instituição? Como você prevê as mudanças que serão trazidas pela proposta curricular atualmente em discussão?

Essas entrevistas foram gravadas em áudio e todas as informações foram transcritas e analisadas qualitativamente.

\section{Corpo técnico-administrativo}

O corpo técnico administrativo da Emem foi representado por dois antigos funcionários da instituição. Essa opção está em consonância com autores que defendem que "a entrevista deve abranger pessoas que sejam depositárias das tradições. Todo agrupamento humano - familiar ou não - tem alguém, quase sempre entre os mais velhos, que guarda a síntese de história do grupo. Esta pessoa é sempre indicada para ser entrevistada" (Meihy, 1996, p. 46).

Assim, esses funcionários foram individualmente submetidos a uma entrevista semiestruturada composta por três questões: Como você avalia a evolução do quadro administrativo da Emem em relação às demandas impostas a este quadro? Em sua opinião, quais fatores afetam o desenvolvimento da atividade administrativa da instituição? Quais sugestões você indicaria aos gestores para um melhor desenvolvimento das atividades administrativas da Emem?

Assim como ocorreu com os professores, as entrevistas com os funcionários foram gravadas em áudio e todas as informações foram transcritas e analisadas qualitativamente.

\section{Corpo discente}

O corpo discente da Emem é formado por alunos dos cursos de Musicalização Infantil, Fundamental - infantil e adulto - e Técnico. O Curso de Musicalização Infantil tem como clientela crianças de 8 e 9 anos. O Curso Fundamental Infantil é destinado a crianças com idade entre 10 e 13 anos e o Fundamental Adulto é destinado a alunos a partir de 14 anos. O Curso Técnico, por sua vez, destina-se a alunos que estejam cursando o Ensino Médio. Esse contingente está dividido entre as 19 modalidades instrumentais oferecidas pela instituição.

Assim, o corpo discente da Emem foi abordado por meio de pesquisa documental e por um questionário administrado aos alunos dos Cursos Fundamental Adulto e Técnico ingressantes nos anos de 2013 e 2014. Para aplicação do questionário foram selecionadas onze turmas perfazendo um total de duzentos alunos. Destaca-se que a investigação por meio do questionário não contemplou alunos dos cursos de Musicalização Infantil e Fundamental Infantil. 
A opção pelos Cursos Fundamental Adulto e Técnico foi justificada pelos seguintes argumentos: 1) Alunos dos cursos de Musicalização Infantil e Fundamental Infantil pertencem a uma faixa etária que exigiria uma abordagem diferenciada por parte dos pesquisadores; 2) o Curso Fundamental Adulto configura-se como o momento central na formação pedagógica oferecida pela escola e, além disso, possui disciplinas coletivas que possibilitam uma certa conveniência na aplicação do questionário; e 3) o Curso Técnico pode ajudar a definir um perfil discente por instrumento. Pelo exposto, percebe-se a adoção de uma técnica de amostragem não probabilística com maior foco no estudo das relações entre variáveis e menor interesse na estimação de valores precisos da população (Cozby, 2006).

O questionário foi constituído por vinte e seis questões, sendo vinte e quatro fechadas e duas abertas. As questões fechadas procuraram levantar características dos sujeitos pesquisados, pois se entende que tais informações configuram-se como um procedimento indicado (Hill; Hill, 2005), e a relação e as expectativas do aluno com a instituição e com o estudo da música. As duas questões abertas versaram sobre a preferências dos alunos pelas disciplinas oferecidas pela Emem.

As informações obtidas por este instrumento de coleta foram tabuladas e categorizadas com objetivos exploratórios e analisadas com 0 auxílio da estatística descritiva.

\section{Análise e discussão dos dados}

Os documentos analisados mostram que a Emem, em seus primeiros quinze anos de funcionamento, padeceu sob a instabilidade da composição de seu corpo docente. Os contratos voláteis e os constantes atrasos no pagamento dos salários dificultaram a fixação de um grupo de professores que pudessem planejar um compromisso de longo prazo com a instituição.

Em 1989 ocorreu a promulgação da Constituição do Estado do Maranhão. Esse texto efetivou, com base no quinto artigo do Ato das Disposições Constitucionais Transitórias, os dezoito professores em atividade naquele momento. Logo após, em 1992, foi realizado o primeiro concurso público para o cargo de professor de Música da Emem. Esse concurso foi realizado para o nível médio e consistiu de uma prova de conhecimentos teóricos na área de Música, porém sem a exigência de formação específica na área. Com os oito aprovados nesse concurso a Emem passou a contar com vinte e seis professores em seu quadro.

O segundo concurso público realizado pela Emem ocorreu dez anos após o primeiro. Esse concurso contemplou as categorias de professor de Música, de nível médio, e de professor de Atividades Artísticas e Culturais, de nível superior. Para esta última categoria foi exigida a formação específica na área de música. Foram oferecidas vagas para as áreas teóricas e também para canto, piano, flauta doce, clarinete, trompete, trombone, saxofone, violão, violino, violoncelo, guitarra, contrabaixo elétrico, bateria, percussão e cavaquinho. Dessa forma, foram nomeados vinte e seis professores de nível médio e seis professores de nível superior. O Núcleo de Música Popular foi criado após a realização desse certame. Assim, a Emem passou a dispor de um corpo docente de cinquenta e oito professores. 
O quadro apresentado atualmente pela Emem mostra um corpo docente formado por quarenta e cinco professores, dos quais um é doutor, três são mestres, quatro são especialistas e treze são graduados. Aponta-se que a recente qualificação do corpo docente da Emem coincide, tanto com a criação das Licenciaturas em Música das Universidades Federal e Estadual do Maranhão, quanto com a abertura de programas de pós-graduação em áreas correlatas à Música.

\section{Informações obtidas pelas entrevistas}

Os professores apontam que os cursos da área de música popular e os cursos da área de música erudita oferecidos pela Emem possuem uma situação diferenciada frente ao mercado de trabalho em São Luís. Os professores afirmam que a política cultural vigente no Maranhão favorece os músicos voltados para a área popular. Nesse contexto, são citados o Carnaval, o São João, o Reveillon, e o aniversário da cidade de São Luís como exemplos. Além disso, os grupos militares e o grupo da Guarda Municipal de São Luís não mantêm instrumentistas de cordas friccionadas em seus quadros. Os professores destacam, também, que bares, restaurantes, igrejas e festas particulares privilegiam a música popular em seus ambientes.

Para reforçar essa diferenciação, os professores lembram que o Maranhão não possui os principais meios de inserção dos egressos dos cursos de música erudita. Ou seja, o Estado não mantém orquestras ou quaisquer outros grupos musicais permanentes, sejam eles vocais ou sinfônicos ${ }^{2}$. Por outro lado, os professores assinalam que escolas e projetos sociais têm atraído os egressos dos cursos de música erudita para a atividade pedagógica. Além disso, os alunos de canto têm encontrado espaço de trabalho, atuando como cantores ou regentes, em coros ou grupos vocais em diversas empresas.

A auto-avaliação feita pelo corpo docente endossa, de forma unânime, a recente qualificação de seu quadro. Todavia, os professores apontam a necessidade de uma diretriz pedagógica atual para orientar os trabalhos em sala de aula e dar unidade à formação dos alunos. Além dessa necessidade, os professores evidenciam outros fatores que afetam o desenvolvimento das atividades pedagógicas da Emem. O espaço físico, a falta de contratação de professores, a falta de autonomia financeira, e o sistema de ingresso de novos alunos merecem destaque no discurso dos professores entrevistados.

A proposta curricular atualmente em discussão, e há muito esperada pela Emem, é considerada positiva pelos professores. A criação do Curso Fundamental - infantil e adulto - e a redução do Curso Técnico para três anos são as mudanças de maior impacto dessa nova proposta. Além disso, há mudanças que contemplam interesses específicos de cada curso, como a inserção de novas disciplinas no currículo, e a atualização, seleção e organização dos conteúdos das disciplinas.

\section{Composição do corpo técnico-administrativo: uma sinopse histórica}

Os primeiros anos de atividade da Emem foram apoiados por um corpo técnicoadministrativo de seis funcionários. A esta época a instituição oferecia quatro cursos

\footnotetext{
2 Há grupos corais que, embora não trabalhem exclusivamente com o repertório considerado erudito, têm atuado em São Luís por mais de duas décadas. O ponto em questão é que esses grupos não são mantidos pelo erário. 
técnicos e o curso de iniciação musical e possuía cento e setenta alunos. Informações obtidas pelas entrevistas com os funcionários apontam que o funcionamento era satisfatório.

Todavia, o crescimento da instituição e as consequentes mudanças para sedes maiores em 1978, 1981 e 2001, aumentou a demanda de técnicos-administrativos. Assim, em 1992 foi realizado um concurso público para atendimento dessa demanda e o quadro da Emem foi ampliado. Contudo, nenhum outro foi realizado pelo Estado para contemplar o setor administrativo.

Atualmente, o corpo técnico-administrativo da Emem é composto por 26 funcionários distribuídos em 8 funções: um bibliotecário, um técnico em assuntos educacionais, um datilógrafo, onze assistentes administrativos, quatro operacionais de serviços diversos, seis vigias, um técnico do estúdio de gravação e um encarregado do serviço de performance e eventos artísticos. Os funcionários das duas últimas funções citadas não compõem o corpo efetivo de servidores do Estado.

\section{Informações obtidas pelas entrevistas}

Os funcionários apontam que a evolução do corpo técnico-administrativo não acompanhou as demandas impostas pelo crescimento da instituição. A impossibilidade de expansão das atividades da Emem para o turno noturno e constantes desvios de função foram destacados como consequência dessa defasagem.

Além disso, os funcionários indicam que os serviços administrativos da Emem são sensíveis às ações da Secretaria de Cultura do Estado do Maranhão - Secma - e que há pouca autonomia administrativa para a gestão da Emem. Nessa seara foram apontadas questões relativas ao atendimento, por parte da Secma, das solicitações feitas pela direção da Emem, e a não participação da gestão da instituição na criação e designação de cargos comissionados que são realizados no âmbito da Secma. Assim, os funcionários entrevistados sugerem o estreitamento da relação institucional entre a Emem e a Secma para que as necessidades da instituição sejam amplamente discutidas no seio da Secretaria de Cultura.

\section{Corpo discente: a procura pela Emem: considerando alguns fatores externos e o número de matrículas}

Inicialmente interessou-se pelo quantitativo de matrículas realizadas pela Emem ao longo dos últimos anos a fim de identificar traços relacionais entre a instituição e sua clientela. Pesquisas documentais mostram que o número de matrículas tem estabelecido, a cada intervalo de tempo, um menor patamar em seu valor absoluto. Na tabela 1 são apresentados esses valores no período compreendido entre os anos de 2004 e $2014^{3}$.

3 Após a detecção de um problema estrutural a Defesa Civil do Estado do Maranhão interditou o prédio onde funciona a Emem e, com isso, todas as atividades da escola foram canceladas ao longo do ano de 2012. Por esse motivo o ano de 2012 não consta na tabela 1. As consequências dessa interdição serão analisadas com mais profundidade adiante. As atividades da escola foram retomadas em 2013. 
Tabela 1 -

Número de matrículas na Emem no período entre 2004 e 2014.

\begin{tabular}{|c|c|c|c|}
\hline Ano & $1^{\circ}$ semestre & $2^{\circ}$ semestre & Total no ano \\
\hline 2004 & 1.074 & 992 & 2.066 \\
\hline 2005 & 1.101 & 1.124 & 2.225 \\
\hline 2006 & 1.205 & 1.114 & 2.319 \\
\hline 2007 & 1.043 & 1.025 & 2.068 \\
\hline 2008 & 904 & 781 & 1.685 \\
\hline 2009 & 667 & 1.008 & 1.675 \\
\hline 2010 & 773 & 553 & 1.326 \\
\hline 2011 & 731 & 589 & 1.320 \\
\hline 2013 & 788 & 519 & 1.307 \\
\hline 2014 & 510 & 560 & 1.070 \\
\hline
\end{tabular}

Fonte: Ferreira, 2014, p. 142.

$\mathrm{Na}$ busca de um entendimento dos motivos pelos quais tem ocorrido essa diminuição no número de matrículas ventilaram-se diversas variáveis externas com probabilidade de influenciar esse comportamento: criação tanto da Escola Municipal de Música de São Luís - Emmus - quanto dos cursos de graduação em música da Universidade Estadual do Maranhão - Uema - e da Universidade Federal do Maranhão UFMA -, os reflexos da promulgação da Lei Federal 11.769/2008 e os efeitos da gestão política em anos eleitorais.

A Emmus foi criada pela lei municipal n. 4.561/2005 e manteve suas atividades até o ano de 2012 (Santos Neto, 2013). Nesse ínterim percebe-se um aumento no número de matrículas da Emem ao longo do primeiro ano de funcionamento da Emmus. Além disso, embora esse número tenha diminuído nos cinco anos subsequentes, essa tendência de queda não foi interrompida com o encerramento das atividades da Emmus. Essas informações sugerem que a Emmus não concorreu com a Emem nesse período e, por conseguinte, não exerceu nenhuma influência negativa no comportamento dos dados observados.

Por outro lado, espera-se que a criação de cursos de graduação em Música, como ocorreu com a Uema em 2005 e com a UFMA em 2006, sirva como estímulo para uma sólida preparação na área em uma instituição especializada. O mesmo idealiza-se sobre a promulgação de uma lei federal que fomente o ensino de música nas escolas. Contudo, nem a criação dos cursos de graduação, nem a promulgação da lei n. 11.769/2008 foram capazes de sustentar o número de matrículas da Emem. Dessa forma, é razoável ponderar que não se pode atribuir a esses fatores alguma influência positiva sobre o número de matrículas.

Como última variável externa analisada avaliaram-se os efeitos das gestões políticas em âmbito municipal e estadual em anos eleitorais. Para identificar alguma correspondência entre ano e número de matrículas, a variável ano foi codificada como variável nominal dicotômica - anos pares = eleitoral e anos ímpares = não eleitoral - e sua relação com o número de matrículas foi investigada pelo método estatístico do cálculo do coeficiente de correlação ponto-bisserial. Assim, essa análise retornou o valor de rpb = 
0,021 para $\alpha=0,05$, o que indica que a correlação obtida é significante 4 . Em outras palavras,os dados sugerem que o número de matrículas da Emem é suscetível ao comportamento político em anos eleitorais, o que reforça a sensibilidade da instituição às questões políticas oriundas de instâncias superiores, como foi apontado nos dados coletados na entrevista com os técnicos administrativos.

\section{Uma investigação sobre o perfil discente}

Historicamente os cursos mais procurados têm sido Canto, Piano e Violão Erudito. Todavia, desde a implantação do Núcleo de Música Popular a outrora presença quase hegemônica desses cursos agora divide espaço com cursos de Guitarra, Violão Popular e Contrabaixo Elétrico. Como destacado nas entrevistas realizadas pelos professores vê-se que o Núcleo de Música Popular tem atendido uma expressiva demanda da sociedade. Pela tabela 2 se mostra o total de matrículas dos seis cursos mais procurados no ano de 2014.

Tabela 2 -

Número de matrícula por instrumento musical no ano de 2014.

\begin{tabular}{|c|c|}
\hline Instrumento & Número de matrículas \\
\hline Guitarra & 63 \\
\hline Violão Clássico & 61 \\
\hline Piano & 55 \\
\hline Violão Popular & 50 \\
\hline Canto & 43 \\
\hline Contrabaixo Elétrico & 38 \\
\hline
\end{tabular}

Fonte: Ferreira, 2014, p. 131.

Em termos de perfil discente percebe-se que o alunado é majoritariamente masculino (70\%), mais da metade vive em áreas com baixos indicadores socioeconômicos e está razoavelmente compreendido em uma faixa etária entre 16 e 20 anos (40\%). Além disso, dados extraídos dos questionários evidenciaram que o primeiro contato desses alunos com a música aconteceu em ambiente familiar ou na igreja ( $40 \%$ para cada um dos casos), e que as primeiras informações sobre a Emem vieram por meio de pessoas próximas (amigos: 70\%, e família: 15\%).

Esses percentuais mostram que há algumas questões que devem ser objeto de reflexão da gestão da escola. Em primeiro lugar deve-se discutir os motivos pelos quais há uma predominância do sexo masculino na composição do corpo discente. Entende-se que políticas de igualdade de gênero devem sempre ser pauta da gestão pública, em especial quando se discute temas na seara educacional.

\footnotetext{
4 Note-se que essa análise não exclui a possibilidade de outras variáveis, inclusive aquelas internas à instituição influenciarem no comportamento observado. Além disso, salienta-se que o ano de 2012 não foi considerado no cálculo da correlação entre ano e número de matrículas. Informações sobre o uso de ferramentas estatísticas aplicadas à musicologia podem ser encontradas em Beran (2004). 
Outrossim, reforça-se o importante papel social cumprido pela Emem no atendimento a seu corpo discente. Como boa parte desse corpo é oriundo de áreas com baixos indicadores sociais, a instituição deve, recorrentemente, pensar meios de permanência desses alunos com vistas a obter uma maior taxa de diplomação ${ }^{5}$.

Além disso, uma maior incidência de adolescentes no corpo discente e a evidente participação da família na iniciação musical e na indicação da Emem como opção de formação na área faz com que a família torne-se elemento fundamental no sucesso de cada aluno. Os dados obtidos ratificam que

a família é, assim, a primeira instituição de iniciação musical do indivíduo. Os hábitos da família condicionarão as práticas de seus filhos, já que estes são formados cognitivamente em um processo que envolve a imitação das atitudes daqueles que estão ao seu redor e que este toma como padrão. (Amato, 2010, p. 166)

Dessa forma sugere-se que a taxa de diplomação seja positivamente relacionada à participação familiar na vida do aluno dentro da Emem, pois entende-se que, para a família "há sempre alguma maneira de influenciar, seja expressando abertamente a opinião, muitas vezes pressionando o filho a seguir determinada profissão, seja de maneira mais sutil ou manipuladora" (Almeida; Pinho, 2008, p. 174).

O questionário avaliou, por meio de uma questão dicotômica sim ou não, se os alunos conheciam o currículo pedagógico da instituição. Por uma questão tipo Likert foi investigado o grau de satisfação dos alunos com o ensino oferecido pela Emem. Essas duas variáveis foram correlacionadas com o intuito de verificar se o conhecimento da proposta pedagógica da instituição exerce alguma influência na percepção da qualidade do ensino. Os dados estudados sugerem que conhecer o currículo da Emem não muda essa percepção sobre a qualidade ${ }^{6}$.

${ }^{5} \mathrm{~A}$ fonte das informações sobre os indicadores sociais relativos aos bairros de residência dos alunos é o site do Observatório Social de São Luís: http://nossasaoluis.org.br/slz2014/area 00 .html.

6 O coeficiente de correlação entre as respostas Sim e as respostas Não é $r=0,9986$. Como pode ser visualmente observado a partir da tabela essa forte e positiva relação na percepção da qualidade do ensino da Emem entre os alunos que conhecem e os que não conhecem a proposta pedagógica da instituição indica que o comportamento do aluno não é alterado quando confrontado com essas variáveis. v. 6 n. 12 Maio/ago. 2017 p. $43-58$ 
Figura 1 -

Correlação entre a percepção da qualidade do ensino e o conhecimento do currículo.

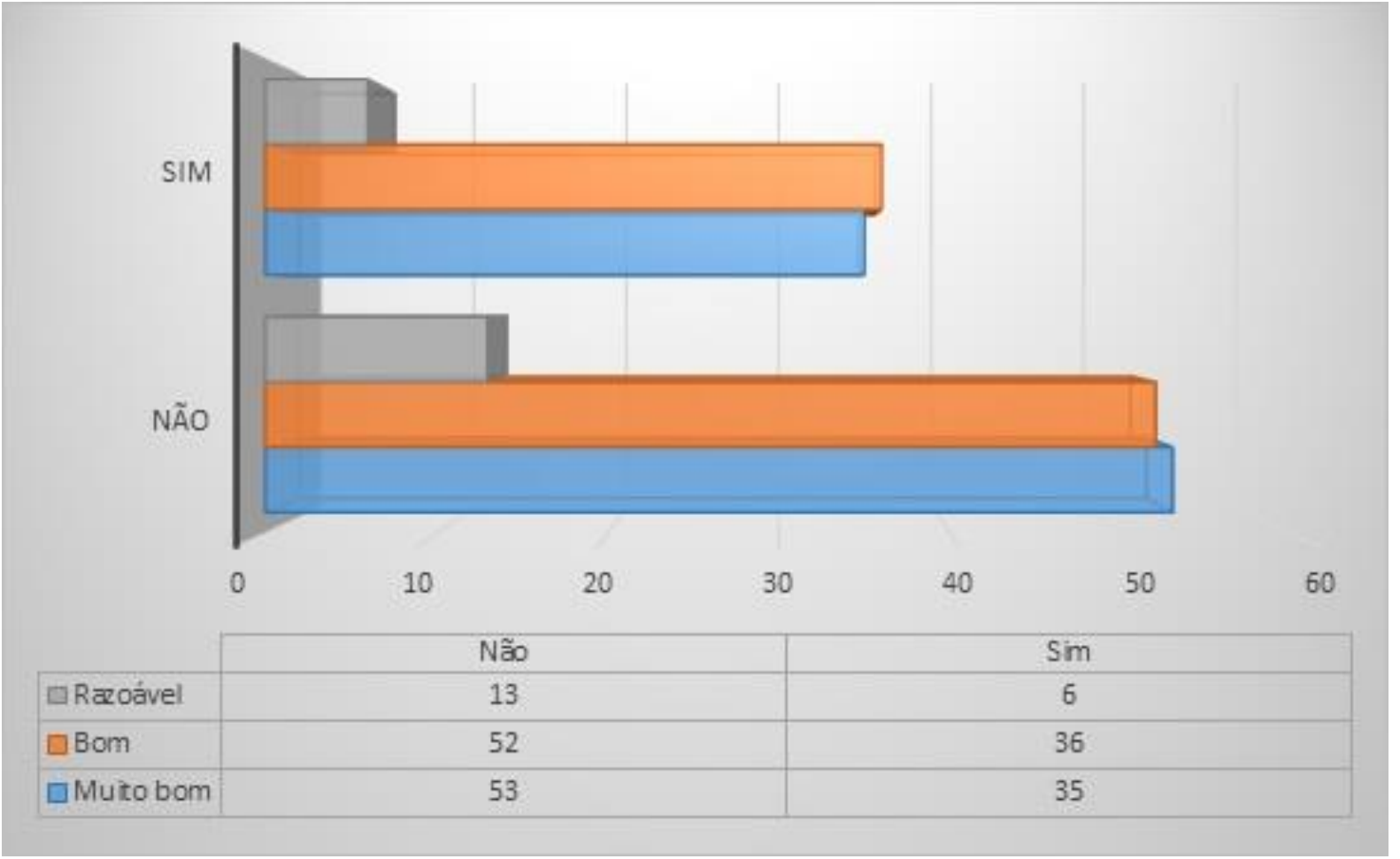

O conhecimento do currículo também foi correlacionado às preferências demonstradas pelo corpo discente. Nesse sentido, o questionário solicitou aos alunos que assinalassem, a partir de uma lista previamente constituída, as disciplinas preferidas e as disciplinas que menos gostavam no curso em que estavam matriculados.

O comportamento do corpo discente da Emem em relação às disciplinas preferidas parece não sofrer influência do fato de o aluno conhecer ou não o currículo da instituição ${ }^{7}$. Independente do conhecimento do currículo, a maior parte dos alunos assinalou que há várias atividades entre as suas preferidas, em especial o estudo do instrumento.

7 O coeficiente de correlação entre as respostas Sim e as respostas Não é r=0,9924. Vide nota de rodapé anterior. 
Figura 2 -

Correlação entre as disciplinas preferidas e o conhecimento do currículo.

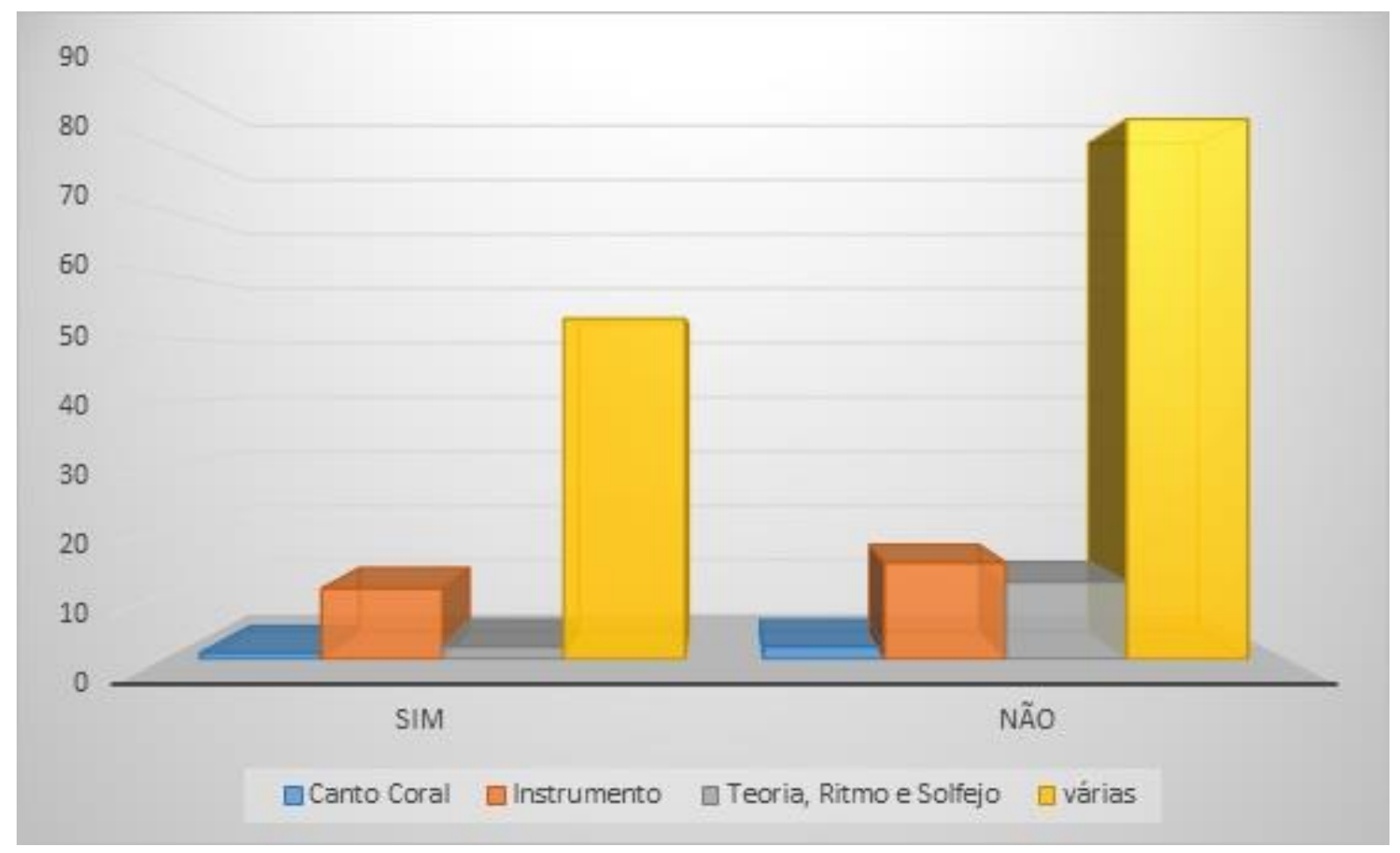

Todavia, o fato de não conhecer o currículo parece afetar a percepção das atividades que os alunos menos gostam de desenvolver na instituição ${ }^{8}$. Evidencia-se 0 elevado número de alunos que evitaram responder essa questão. Como uma análise possível esse dado indica que o desconhecimento do currículo não oferece aos alunos as condições necessárias para tal avaliação. Complementarmente sobre os alunos que não tiveram contato com a proposta pedagógica da Emem parece pairar um maior desconhecimento acerca da importância do Canto Coral na formação musical. Os dados mostram que, em relação aos alunos que conhecem o currículo, quase o dobro dos que não conhecem tem essa disciplina como a menos preferida. A necessidade de discussão sobre currículo é endossada por pesquisas desde a formação inicial até cursos em nível superior em educação musical (Pereira, 2014; Sobreira, 2014). 
Figura 3 -

Correlação entre as disciplinas menos preferidas e o conhecimento do currículo.

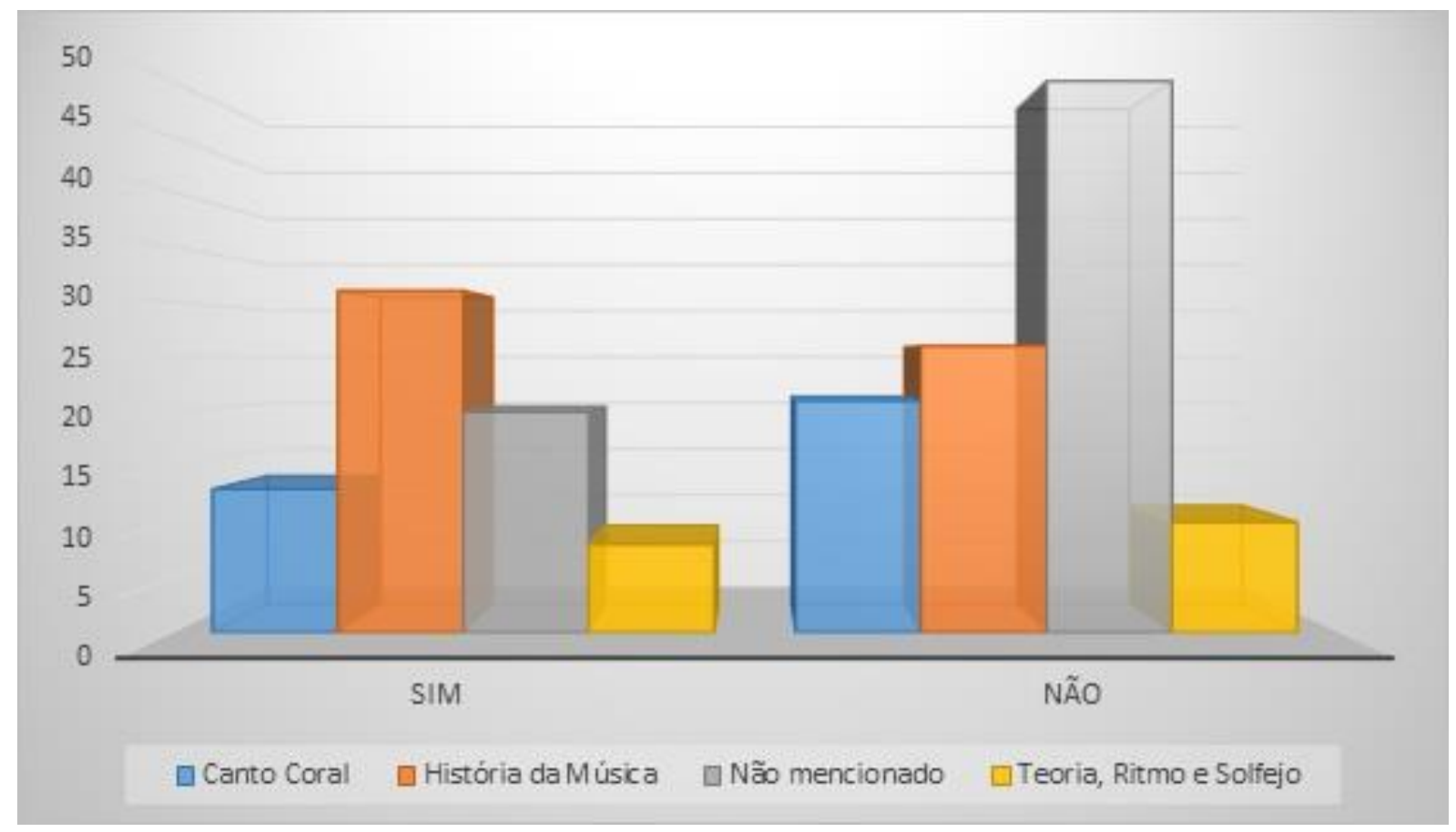

A parte final do questionário, formada por duas questões abertas, solicitou aos alunos que elencassem três pontos positivos e três pontos negativos acerca do ensino de música na Emem. A categorização dos pontos positivos elencados pelos alunos reforça, principalmente, a contribuição da qualificação do corpo docente, fato também apontado na entrevista com os professores. Os pontos negativos, por sua vez, compreenderam a estrutura física, a falta de recursos materiais e um serviço de informações que não atende as expectativas do corpo discente.

A estrutura física da Emem merece uma reflexão especial. Em 2012 a Defesa Civil do Estado do Maranhão interditou o prédio que abrigava a instituição. Por se tratar de uma construção tombada pelo Instituto do Patrimônio Histórico e Artístico Nacional há cuidados especiais e limites para quaisquer obras de reparação e adequação dos espações físicos. Dessa forma, o prédio permaneceu interditado durante todo o ano de 2012 e, até hoje, o quarto pavimento, que conta com oito salas com tratamento acústico adaptadas para o trabalho de instrumentos de sopro, permanece fechado. Pelo exposto, a estrutura física ser elencada como ponto negativo era um dado esperado.

Os outros dois pontos negativos sugerem a necessidade de uma otimização das relações interinstitucionais e das relações intra-institucionais. A falta de recursos materiais pode ser mais um reflexo da pouca autonomia administrativa apontada na entrevista com o corpo técnico-administrativo. Além disso, as reclamações direcionadas ao serviço de informações indicam a necessidade de elaboração e publicização de um regimento interno que oriente procedimentos para questões pertinentes à vida na instituição. 


\section{Sugestões e considerações finais}

O presente estudo reforça a importância da Emem no contexto da educação musical do Maranhão. A elevada qualificação docente, a preocupação com o contexto musical do Estado e a ampliação da oferta de vagas e de modalidades instrumentais são aspectos fundamentais no lugar de destaque ocupado pela instituição. Todavia, diante da problemática levantada no escopo deste trabalho, percebe-se que há ações da gestão da escola e outras ações administrativas de ordem geral, que podem fortalecer seu material humano e, por conseguinte, incidir no índice de evasão discente. Essas ações são elencadas em três dimensões: a relação administrativa com as instâncias superiores, decisões colegiadas e ações no campo pedagógico.

Propõe-se que haja um trabalho de gestão junto às instâncias superiores no sentido de criar mecanismos de valorização da qualificação docente no âmbito da instituição. A qualificação docente foi enfaticamente apontada como positiva pelos corpos docente e discente e o incentivo à continuidade dessa qualificação, seja por meio de retribuição salarial, seja por outro meio legal que proporcione aos professores possibilidades de uma capacitação continuada, tende a refletir positivamente na permanência do discente na instituição.

Também no nível da gestão junto às instâncias superiores há a necessidade de uma busca por maior autonomia administrativa da Emem. Essa busca inclui a elaboração de uma legislação estadual complementar que discipline a relação da instituição com suas instâncias superiores naquilo que concerne ao orçamento; atribuições de funções comissionadas; criação de vagas e reposição de recursos humanos; etc. Entende-se que uma maior autonomia pode fomentar um atendimento administrativo às demandas pontuais e específicas que podem ser apresentadas pelo corpo discente.

Além disso há questões que podem ser decididas em âmbito colegiado: sugere-se a publicização e a efetiva aplicação do regimento interno da instituição para disciplinar os trâmites administrativos dos diversos processos inerentes à rotina diária da instituição. Complementarmente, há que se capacitar os servidores técnicos para a instrução de tais processos e para o bom tratamento da vida acadêmica de professores e alunos.

No campo pedagógico sugere-se a adoção de algumas políticas estudantis e um maior envolvimento do corpo discente com o currículo da Emem. Os dados coletados indicam que a instituição pode adotar uma política que vise uma maior igualdade de gênero entre os alunos. Além disso, por atender a uma clientela oriunda de áreas com baixos indicadores sociais, é interessante que a Emem adote algumas estratégias que contribuam com a permanência do aluno na instituição. Essas estratégias podem vir na forma de bolsas para participação nos grupos instrumentais da Emem, programas de monitoria, parcerias externas para o estabelecimento de programas de estágio, etc.

Por último, indica-se que, assim que o novo currículo for finalizado, o corpo discente seja aproximado da proposta pedagógica da Emem. Isso pode se dar por meio de uma semana pedagógica, onde as relações entre as diferentes atividades desenvolvidas podem ser melhor explicitadas, ou através atividades integradas entre as diferentes disciplinas ao longo do ano letivo. Pelo exposto, espera-se que o presente trabalho aponte caminhos para a Emem, em especial, e para instituições congêneres que possam, por ventura, vivenciar situações semelhantes. 


\section{Referências}

ALMEIDA, Maria Elisa Grijó Guahyba de; PINHO, Luís Ventura de. Adolescência, família e escolhas: implicações na orientação profissional. Psicologia clínica [online], v. 20, n. 2, 2008, p. 173-184.

ALVES-MAZZOTTI, Alda Judith. Usos e abusos dos estudos de caso. Cadernos de Pesquisa, v. 36, n. 129, 2006, p.637-651.

AMATO, Rita de Cássia Fucci. Memória musical: retratos de um conservatório. São Paulo: Annablume, 2010.

BERAN, Jan. Interdisciplinary statistics: statistics in musicology. London: Chapman \& Hall/CRC, 2004.

COZBY, Paul. Métodos de pesquisa em ciências do comportamento. São Paulo: Atlas, 2006.

COSTA, Lisiane Nina de Araújo. Escola de música do Estado do Maranhão: uma abordagem histórica. São Luís: UFMA, 1995. 95f. TCC (licenciatura em Educação Artística). Universidade Federal do Maranhão. São Luís, 1995.

D'ABREU, Lylla Cysne Frota; MARTURANO, Edna Maria. Associação entre comportamentos externalizantes e baixo desempenho escolar: uma revisão de estudos prospectivos e longitudinais. Estudos de Psicologia, v. 15, n. 1, 2010, p. 43-51.

FERREIRA, Ana Neuza Araújo. O Ensino de Música no Nordeste: um estudo históricoorganizacional sobre a Escola Lilah Lisboa de Araújo em São Luís do Maranhão. São Luís: UFMA, 2014. 167f. Dissertação (mestrado em Cultura e Sociedade). Universidade Federal do Maranhão. 2014.

GOLDENBERG, Miriam. A arte de pesquisar: como fazer pesquisa qualitativa em Ciências Sociais. Rio de Janeiro: Record, 2004.

HILL, Manuela Magalhães; HILL, Andrew. Investigação por questionário. Lisboa: Silabo, 2005.

MEIHY, José Carlos Sebe Bom. Manual de história oral. São Paulo: Loyola, 1996.

PIMENTEL, Maria Odília de Quadros. Traços de percursos de inserção profissional: um estudo sobre egressos dos Conservatórios Estaduais de Música de Minas Gerais. Revista da Abem, Londrina, v. 23, n. 35, 2015, p. 76-88.

RODRIGUES, Andréa Lúcia dos Santos Ferreira. O Curso Básico Infantil de Piano da Escola de Música do Estado do Maranhão. São Luís: UFMA, 2011. 87f. TCC (licenciatura em Música). Universidade Federal do Maranhão.

SILVA, Glícia Lorainne Moreira. Escolha de repertório: um estudo com professores de violão da Escola de Música do Estado do Maranhão Lilah Lisboa. São Luís: UFMA, 2015. 125f. TCC (licenciatura em Música). Universidade Federal do Maranhão.

SOBREIRA, Silvia Garcia. Conexões entre a educação musical e o campo do currículo. Revista da ABEM, Londrina, v. 22, n. 33, 2014, p. 95-108.

SUBTIL, Maria José Dozza. Reflexões sobre formação de professores: expectativas e pré-formação de licenciandos em música e artes visuais. Cadernos de Educação, Pelotas, n. 40, 2011, p. 79-94.

TRIVIÑOS, Augusto Nibaldo Silva. Introdução à pesquisa em ciências sociais: a pesquisa qualitativa em educação. São Paulo: Atlas, 2012.

YIN, Robert. Estudo de caso: planejamento e métodos. Porto Alegre: Bookman, 2005. 
ZORZAL, Ricieri Carlini Zorzal; FERREIRA, Ana Neuza Araújo. O ensino de música no nordeste brasileiro: perspectivas históricas e desafios atuais. Revista Brasileira de História da Educação, Maringá, v. 16, n. 4, 2016, p. 155-189.

Ricieri Carlini Zorzal é professor adjunto no Departamento de Artes da Universidade Federal do Maranhão e coordenador do Grupo de Pesquisa em Ensino e Aprendizagem da Performance Musical. Atualmente desenvolve, com apoio financeiro da Fapema e do CNPq, investigações sobre estratégias de ensino em masterclasses de violão.

Endereço: Avenida dos Portugueses, 1966 - 65080-805 - São Luís - MA - Brasil.

E-mail: ricieri@pq.cnpq.br.

Ana Neuza Araújo Ferreira é professora de Piano na Escola de Música do Estado do Maranhão. Concluiu, em 2014, o mestrado em Cultura e Sociedade na Universidade Federal do Maranhão.

Endereço: Rua da Estrela, 363 - 65010-200 - Grande, São Luís - São Luís - MA Brasil.

E-mail: ananeuza@hotmail.com.

Recebido em 22 de janeiro de 2017.

Aceito em 14 de junho de 2017. 